\title{
Endogenous Attention in Normal Elderly, Presymptomatic Huntington's Disease and Huntington's Disease Subjects
}

\author{
Charles-Siegfried Peretti ${ }^{1,3}$, Charles Peretti ${ }^{1}$, \\ Virginie-Anne Chouinard 2,3 and Guy Chouinard 3,4 \\ ${ }^{1}$ Service de Psychiatrie, Hôpital Saint-Antoine, Université Pierre et Marie Curie, Paris, \\ ${ }^{2}$ Massachusetts General Hospital/McLean Adult Psychiatry, \\ Residency Training Program, Harvard Medical School, Boston, Massachusetts, \\ ${ }^{3}$ Clinical Psychopharmacology Unit, McGill University, Montreal, \\ ${ }^{4}$ Fernand Seguin Research Center, University of Montreal, Montreal, \\ ${ }^{1}$ France \\ 2USA \\ 3,4Canada
}

\section{Introduction}

\subsection{Definition and fragmentation of attention}

Attention is a cognitive process sensitive to the effects of aging and neurodegenerative diseases, and its decline contributes to a decrease in cognitive performances during aging1-4. Attention is viewed as a set of different components derived from the Posner's model rather than a global unitary model 5 . Visuospatial attention is divided into explicit or implicit attention depending on the presence or absence of awareness ${ }^{6,7}$. Attention is also classified as exogenous and endogenous attention. Exogenous or automatic attention is directed by external stimuli, whereas endogenous or voluntary attention is directed by voluntary acts. Furthermore, shifts of visuospatial attention involve separate processes, such as shift between objects, as opposed to shift within objects ${ }^{8,9}$. The distinction between data-driven attention which is sensitive to aging, and memory-driven attention which is hardly sensitive to aging, also corresponds to the distinction between fluid and crystallized intelligence ${ }^{10}$. These distinctions have been established through findings of impairment caused by aging on subtests of the Wechsler Adult Intelligence Scale (WAIS) measuring data-driven attention (Digit Span, Digit Symbol and Vocabulary subtests), while other WAIS subtests remained unimpaired by aging ${ }^{11,12}$.

Visual perception depends on the occipito-temporal or the "what" pathway for object vision and on the occipital parietal or the "where" pathway for spatial vision ${ }^{13}$. Milner and Goodale ${ }^{14}$ proposed that the "where" pathway or dorsal stream contributes to action control by first selecting the location of an object, and then the ventral stream or the "what" pathway recognizes and analyzes the spatially defined part of the scene ${ }^{15}$. Different models 
of attention describe mechanisms of how visual features (e.g. colour) guide spatial attention and maximum activation ${ }^{16-18}$.

Posner postulated that there are three different types of operations involved in visual attention: disengaging, shifting and engaging19. These have been studied in Alzheimer's disease (AD), Huntington's disease (HD) and Parkinson's disease (PD) ${ }^{20-22}$. In AD, decreased attention has been attributed to a process that accelerates aging deficits, thus altering all cognitive components (memory, language, executive functions, etc.). However, this model does not explain deficits of attention found in normal aging and other neurodegenerative diseases 22,23 . Patients with AD and PD were found to have distinct attention deficits when required to shift attention to targets contained within the same visual stimulus ${ }^{20,21}$. PD patients also had impaired ability in shifting attention as shown by the number of perceptual errors made in identifying target stimuli ${ }^{20}$. The ability of HD patients to shift attention has been less investigated. Nonetheless, cognitive deficits associated with PD and HD tend to be more similar than different, and diseases that affect subcortical structures were found to produce similar patterns (or a similar pattern) of attention deficits 22 .

\subsection{Normal aging of attention}

Studies investigating normal aging of attention have consistently shown that attention declines with age ${ }^{24,25}$. The exogenous component of attention is less impaired by aging as can been seen in simple detection tests when the target is explicitly cued ${ }^{24,25}$. In contrast, the endogenous component of attention is more sensitive to aging in discrimination tests when the target is not explicitly cued. From the age of 75, the effects of age and neurodegenerative diseases on attention are similar ${ }^{25}$, which is largely due to misleading cues increasing reaction time (RT). These results suggest that the decline in attention associated with aging comes from a decreased ability to shift attention $3,23,25$. In AD patients, impaired ability to shift attention was found in both spatial- and object-based attention ${ }^{26}$.

Response latency is shorter when the target is surrounded by congruent flankers (arrows pointing in the correct direction to target location), than when the target is surrounded by arrows pointing in the direction opposite to target location. Target detection latency depends on surrounding stimuli (flankers), which could be congruent or incongruent ${ }^{27}$. Thus, the conflicting nature of the stimulation allows the study of voluntary components of endogenous attention ${ }^{28}$. Furthermore, the anterior region of the Cingulate Gyrus, part of the exogenous attention network, was also found to be activated during perceptual conflicting situations ${ }^{29}$.

\subsection{Attentional neuronal networks}

Exogenous and endogenous attention correspond to separate neuronal networks ${ }^{30}$. Two attentional neuronal networks have been identified: a posterior automatic network which includes the posterior parietal cortex, the thalamus pulvinar nuclei and the superior colliculus ${ }^{31}$, and an anterior executive network which consists of the dorsolateral and ventromedial prefrontal cortex, the anterior Cingulate Gyrus and striatum.

The discovery of posterior and anterior attentional networks has led to a better understanding of normal and pathological aging of attention. If attentional networks do not undergo alterations other than those expected to occur during normal aging, one would 
expect a relative preservation of both endogenous and exogenous attention. In HD with dementia, neurodegeneration occurs in the striatum, putamen and caudate, and is often associated with neuronal death in the prefrontal cortex. In contrast to normal aging, damage to sub-cortical frontal circuits would lead to an alteration of the endogenous attention anterior network, and preservation of the exogenous attention posterior network. In AD, progressive degeneration occurs simultaneously in multimodal association cortex (parietal and prefrontal regions), with impairment of posterior and anterior attentional networks, affecting both endogenous and exogenous attention ${ }^{22}$.

The present study was designed to evaluate these two components of attention in normal aging, presymptomatic Huntington's Disease (presymptomatic HD) and HD.

\section{Methods}

\subsection{Subjects}

\subsubsection{HD patients, presymptomatic HD patients and controls}

The HD group included 10 symptomatic subjects ( 3 women and 7 men) with hyperkinetic rather than hypokinetic symptoms. The age of HD patients ranged from 35 to 47 years $($ mean $=42$ years $[S D=4.2]$ ), and Mattis total score ranged from 110 to 125 (mean=120 [SD=5.8]). Seven presymptomatic HD ( 4 women and 3 men) were included with the transmittable mutation of the gene, IT15, on the short arm of chromosome 432. DNA amplification technique ${ }^{33}$ makes it possible to detect if an allele of the Huntington encoding gene displays repeats of the CAG sequences exceeding the threshold of 37 repeats and thus, detect carriers. The age of the presymptomatic HD group ranged from 35 to 46 years $($ mean=39 years $[S D=3.6]$ ), and Mattis total score ranged from 130 to 145 (mean=137 $[\mathrm{SD}=5.6])$. The control group included 18 patients suffering from various medical conditions (8 women and 10 men) who were tested while awaiting clinical investigation at the MaisonBlanche Hospital of Reims, and for whom the main inclusion criterion was the integrity of frontal and striatal regions. Their mean age was 38 years [SD=4.7] and the mean Mattis total score was 140 [SD=4.1].

The study was funded by a Champagne-Ardenne Regional Grant and approved by the Ethic Committee of the Champagne-Ardenne Region. Participants were informed of the purpose of the research protocols and gave informed written consent. All subjects were tested during the same time period, 2002-2003.

\subsection{Procedures}

\subsubsection{Visuospatial attention protocol}

Protocols derived from Posner's visuospatial orientation model allow the study of the different components of attention $34,6,19,30$. In these protocols, the subject's attention is focused first on the centre of the screen and then to the left or right, using a cue, which is either peripheral (brightness of the place where the target will appear) or central (with an arrow pointing to left or right). The target (a letter to be detected, a side to be localized or a target to be identified) is then presented either to the left or the right. If the target appears on the same side as the preparatory cue, the cue is considered "valid". If it appears on the other side, it is misleading or "invalid". When both sides are simultaneously signalled, the cue is 
considered neutral since it does not permit a preparatory process. In addition to the peripheral or central nature of the cue, other experimental factors may be used: time interval between the cue and target, called cue-target Stimulus-Onset Asynchrony (SOA), which may range from $50 \mathrm{~ms}$ to several seconds, and \% proportion of valid to invalid preparatory cue, which may range from $80 \% / 20 \%, 50 \% / 50 \%$, to $20 \% / 80 \%$.

Results obtained from visuospatial protocols show that RT is shorter for valid compared to neutral cues, and shorter for neutral than for invalid cues ${ }^{35}$. These measurements make it possible to calculate an attention "benefit" by subtracting Neutral RTs minus Valid RTs and an attention "cost" by subtracting Invalid RTs minus Neutral RTs. Subtracting Invalid RTs minus Valid RTs bypasses bias associated with neutral cues ${ }^{36}$, and allows a more global measurement, called the RT difference score ${ }^{37,38}$.

The RT difference score is generally thought to be a relatively pure measure of attention. However, RT difference score may be influenced by eye movements, which we controlled by using a SOA of less than $200 \mathrm{~ms}$ (less than the saccadic eye movement latency). An auditory version of the orientation task can also be used to control this potential bias.

Exogenous attention defined as automatic, involuntary and unaffected by memory load, was studied with 1) a peripheral cue, 2) a brief SOA (<200 ms), and 3) an equal proportion of valid and invalid cues $(50 \% / 50 \%)$. Endogenous executive attention characterised as voluntary, controlled, effortful and affected by memory load was studied with 1) a central cue which permits the subject to decode the symbol presented in the middle of the screen, 2) a long SOA> $200 \mathrm{~ms}$, which allows strategic display of attention, and 3) a higher proportional frequency of valid to invalid cues $(80 \% / 20 \%)$, which allows the subject to display anticipatory attention.

\subsubsection{Audiovisual congruence}

To evaluate endogenous attention, an additional procedure was used. Subjects were asked to watch a stimuli on a screen and heard the stimuli through earphones. Targets were designed to combine both auditory and visual modalities in "congruent" and "incongruent" situations. These compound stimuli consisted of everyday objects or actions (a dog barking, a drum roll, a liquid being poured into a glass, etc.). Two such compound stimuli were presented simultaneously. In congruent situations, corresponding auditory and visual stimuli were presented on the same side (e.g. an image of a dog barking to the left, and the sound of the barking in the left ear, together with the image of a drum to the right and the sound of the drum roll in the right ear). In incongruent situations, corresponding stimuli are dissociated (image of the dog to the left, and the sound of barking in the right ear, image of the drum to the right, and the sound of drum in the left ear). The preparatory cue in such tests, occurring $350 \mathrm{~ms}$ before the target, was a pointer either to right or left, or in neutral condition favouring neither side. These pointers could be a pair of eyes looking right, left or straight ahead, or a dog "pricking up its ears" to right or left, or with lowered ears. The subject's task was to identify as quickly as possible the side of one of the target stimuli. Thus, prior to each trial, and throughout the trial, there would be a question on-screen such as: "On which side do you see the dog?" or "In which ear do you hear the drum roll?". Given the configuration of question (cue and target), the cue could be a valid one or an invalid (misleading) one. When the cue is valid, the target is presented on the cued side of 
the target presentation. When it is invalid, the target is presented on the opposite side. All four combinations of congruent/incongruent and valid/invalid were assessed. Congruent and incongruent conditions occurred randomly, each in $50 \%$ of the trials. Valid and invalid trials occurred randomly in $75 \%$ and $25 \%$ of the trials respectively. The procedure has been described in detail by Camus and Gely-Nargeot ${ }^{24}$.

\subsubsection{Statistical methods}

Dependent variables were the recorded RTs ${ }^{1}$ and RT difference scores ${ }^{37}$. To reduce the effect of extreme values, we used the median RT per experimental condition (usual procedure with this type of data). We calculated the median RT difference score, defined as the difference between median Invalid RT minus median Valid RT for each experimental condition. We also calculated an Index by dividing the RT difference score by the overall RT mean for matching valid and invalid trials. This adjustment, recommended by Faust and Balota1, consists of calculating the Proportional Cue Effect expressed as the proportion of Invalid RT minus Valid RT divided by the overall mean RT.

Statistical significance was defined at an alpha level less than 0.05 and all tests were twotailed tests.

Results were submitted to factorial analysis of variance (ANOVA) using age groups, cue validity (valid versus invalid RT), congruence (congruent versus incongruent RT) and modality (auditory versus visual) as factors. For each analysis of variance (ANOVA) the following orthogonal comparisons were made: 1) main effect of age, 2) main effect of cue validity, 3) main effect of congruence, 4) main effect of modality, and 5) their interactions. As a test of statistical significance, each comparison was compared with the error mean square by means of an F test. An F test was made for individual "a priori" comparisons. In addition, to evaluate the differences between HD, presymptomatic HD and controls, independent Student $\mathrm{t}$-tests were performed to compare the means between groups.

\section{Results}

\subsection{HD patients}

ANOVA analyses of RTs for endogenous attention revealed a statistically significant main effect of group $(\mathrm{F}=19.61, \mathrm{df}=2,34, \mathrm{p}<0.001)$, a significant main effect of cue validity $(\mathrm{F}=18.34$, $\mathrm{df}=1,34, \mathrm{p}<0.001)$ and a significant main congruence effect $(\mathrm{F}=11.89, \mathrm{df}=1,34, \mathrm{p}<0.01)$. The interaction of group and cue validity was significant $(\mathrm{F}=6.35, \mathrm{df}=2,34, \mathrm{p}<0.01)$ due to the greater effects of cue validity in HD and presymptomatic HD patients compared to controls. However, we did not observe significant interactions between group and congruence $(\mathrm{F}=2.27, \mathrm{df}=2,34, \mathrm{p}=0.49)$ and cue validity and congruence $(\mathrm{F}=0.73, \mathrm{df}=1,34, \mathrm{p}=0.39)$.

Analyses of RT difference score revealed that the RT difference score of HD patients (mean=810 ms [SD=863]) were significantly $(t=3.54, d f=26, p<0.002)$ different from those of the control group (mean=93 ms [SD=92]). Presymptomatic HD RT difference score (mean=339 ms [SD=397]) did not differ significantly $(\mathrm{t}=-1.34, \mathrm{df}=15, \mathrm{p}=0.20)$ from HD RT difference score $($ mean $=810 \mathrm{~ms}[\mathrm{SD}=863])$, but were also significantly $(\mathrm{t}=2.54, \mathrm{df}=23, \mathrm{p}<0.02)$ different from controls (mean=93 ms [SD=92]) (Figure 1). 


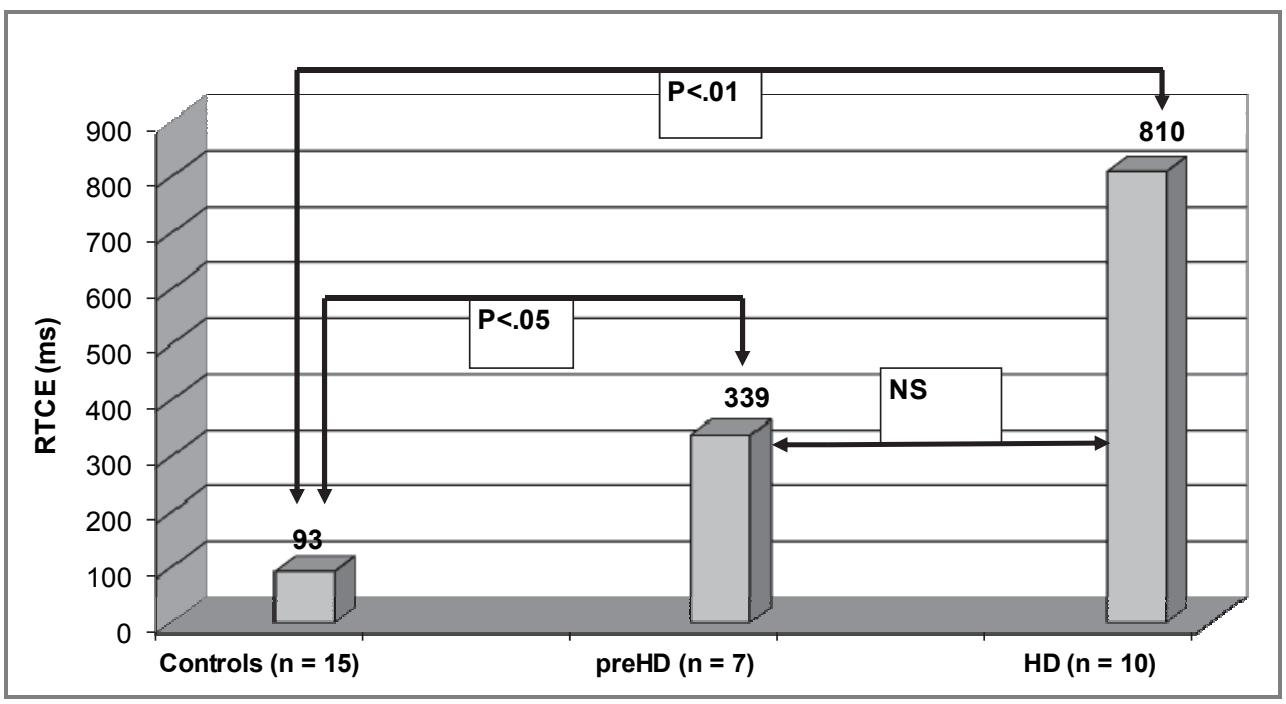

Fig. 1. Mean RTCE (Valid minus Invalid cue RT) in Huntington's Disease (HD), presymptomatic HD patients and matched healthy controls in the Audiovisual cued target condition.

\section{Comment}

\subsection{Attention abnormalities in presymptomatic HD and HD}

We found attention deficits in the endogenous component of attention in patients with HD. While patients with HD did not exhibit attention deficits in exogenous attention, they showed a significant increase in RT difference scores (RT difference between invalid and valid cues) compared to controls. These results for endogenous attention are similar to those obtained in normal elderly subjects. However, the results adjusted by Proportional Cue Effect of mean RT are no longer abnormal in the normal elderly group, while they remain abnormal in patients with $\mathrm{HD}$ who have a proportional cue effect of 0.37 compared to controls with a proportional cue effect of 0.05. This suggests that abnormalities observed in normal aging are limited to selective situations, whereas those observed in HD are the manifestations of a pathological deficit. HD patients have shown deficits in engaging attention 22 and our findings in HD patients are in agreement with these results22.

Attention impairment has been consistently reported in patients with $\mathrm{HD}^{39}$. However, it is unclear if HD attention deficits are independent or associated with other memory deficits (episodic memory), or language difficulties (verbal fluency). Our study showed deficits in both patients with HD and presymptomatic HD, thus their attention disorders would not depend on the progression of dementia. CAG trinucleotides exceeding the threshold of 37 repeats express abnormally high number of glutamates in the huntingtin protein ${ }^{33}$ and are present in both HD and presymptomatic HD patients; which can explain our similar results obtained with both HD and presymptomatic HD patients. 
The most common forms of HD are characterized by the appearance of involuntary choreic movements in sub-cortico-frontal dementia. Many of the prominent hyperkinetic symptoms of early HD can be understood as an inability to suppress dominant response tendencies such as ballism and coprolalia. Patients with HD are impaired on the antisaccade paradigm which tests subjects' ability to suppress automatic saccadic eye movement. One theory to explain attention disorders in HD proposes that the caudate-putamen degeneration impairs functioning of the fronto-subcortical loops, resulting in disruption of the anterior attention network. Within the framework of Posner's model, there would be a dissociation between preserved exogenous and impaired endogenous attention components.

In summary, normal aging was characterized by impaired attention in situations of endogenous or voluntary attention, particularly in perceptual conflict situations. However, this impairment is no longer significant when the data are proportionally cue adjusted. In presymptomatic HD and HD, the endogenous component was also found to be impaired in situations of perceptual conflict, but remains markedly impaired after the data are proportionally cue adjusted.

Theories proposing that attention deficits are the result of a slowing of cognitive processes or a decrease of attentional resources are not supported by our findings. In the present study, cue effects were estimated by calculating RT differences between invalid and valid cues, thus correcting for for the confounding effects of motor-sensory and other nonattention components on RT values. During audio-visual congruent situations, endogenous voluntary attention was preserved in normal aging as well as in HD, and attention abnormalities appeared in situations of perceptual conflict, indicating that some endogenous components were preserved while others were impaired. The theory of attention deficit through depletion of attention resources does not allow for these distinctions to be made.

The proposed model of attention includes components that might respond differently to the effects of age and to cortical/sub cortical neurodegeneration. Such a model has the following advantages: 1) defining cognitive attention by updating former approaches; 2) providing a methodology to investigate and to measure attention abnormalities; and 3) permitting integration of data obtained from brain neuroimaging and cognitive neurosciences. The model proposed allows the separation of attention pathologies and the distinction of pathological categories, thus improving clinical evaluations of the patients.

\section{References}

[1] Faust ME, Balota DA. Inhibition of return and visuospatial attention in healthy older adults and individuals with dementia of the Alzheimer type. Neuropsychology 1997;11:13-29.

[2] Festa-Martino E, Ott BR, Heindel WC. Interactions between phasic alerting and spatial orienting: effects of normal aging and Alzheimer's disease. Neuropsychology 2004;18:258-68.

[3] Greenwood PM, Parasuraman R, Alexander GE. Controlling the focus of spatial attention during visual search: effects of advanced aging and Alzheimer disease. Neuropsychology 1997;11:3-12. 
[4] Langley LK, Overmier JB, Knopman DS, Prod'Homme MM. Inhibition and habituation: preserved mechanisms of attentional selection in aging and Alzheimer's disease. Neuropsychology 1998;12:353-66.

[5] Camus J: Neuropsychologie de l'attention. L'apport des réseaux attentionnels neurocérébraux. Revue de Neuropsychologie 1998;8:25-51.

[6] Posner MI, Cohen Y. Components of visual Orienting. In Attention \& Performance, Vol X. Edited by Bouma H, Bowhuis D. Hillsdale, NJ: Erlbaum, 1984,pp 551-556.

[7] Posner MI, Snyder C. Attention and Cognitive Control. In Information, processing and cognition: The Loyola Symposium.Edited by Solso R. Hillsdale, NJ: Erlbaum, 1975,pp 55-85.

[8] Driver J, Baylis G. Attention and visual object segmentation. In The Attentive Brain. Edited by Parasuraman R. Cambridge, MA: MIT Press, 1998,pp 299-325.

[9] Humphreys GW, Riddoch M. Attention to within object and between object spatial representations: multiple sites for visual selection. Cognitive Neuropsychology 1994;11:207-241.

[10] Rabbitt P. Crystal Quest: a search for the basis of maintenance of practiced skills into old age. In Attention: selection, awareness and control. Edited by Baddeley A, Weiskrantz L. Oxford: Clarendon Press, 1993.

[11] Stankov L. Aging, attention, and intelligence. Psychol Aging 1988;3:59-74.

[12] Van Zomeren A, Brouwer W. Assessment of Attention. In A Handbook of neuropsychological assessment. Edited by Crawford J, Parker D, McKinley W. Hove, UK, Erlbaum, 1994,pp 241-266.

[13] Mishkin M, Ungerleider L, Macko K. Object vision and spatial vision: Two cortical pathways. Trends in Neurosciences 1983;6:414-417.

[14] Milner AD, Goodale MA. Visual pathways to perception and action. Prog Brain Res 1993;95:317-37.

[15] Koch C, Ullman S. Shifts in selective visual attention: towards the underlying neural circuitry. Hum Neurobiol 1985;4:219-27.

[16] Hamker FH. A dynamic model of how feature cues guide spatial attention. Vision Res 2004;44:501-21.

[17] Treisman A, Sato S. Conjunction search revisited. J Exp Psychol Hum Percept Perform 1990;16:459-78.

[18] Wolfe JM, Cave KR, Franzel SL. Guided search: an alternative to the feature integration model for visual search. J Exp Psychol Hum Percept Perform 1989;15:419-33.

[19] Posner MI, Petersen SE. The attention system of the human brain. Annu Rev Neurosci 1990;13:25-42.

[20] Filoteo J, Delis D, Demadura T, Salmon D, Roman M, Shults C. Abnormally rapid disengagement of covert attention to global and local stimulus levels may underlie the visual-perceptual impairment in patients with Parkinson's disease. Neuropsychology 1994;8:218-226.

[21] Filoteo JV, Delis DC, Massman PJ, Demadura T, Butters N, Salmon DP. Directed and divided attention in Alzheimer's disease: impairment in shifting of attention to global and local stimuli. J Clin Exp Neuropsychol 1992;14:871-83. 
[22] Filoteo JV, Delis DC, Roman MJ, Demadura T, Ford E, Butters N, Salmon DP, Paulsen J, Shults CW, Swenson M, Swerdlow N. Visual attention and perception in patients with Huntington's disease: comparisons with other subcortical and cortical dementias. J Clin Exp Neuropsychol 1995;17:654-67.

[23] Parasuraman R, Greenwood P. Selective attention in aging and dementia. In The Attentive Brain. Edited by Parasuraman R. Cambridge, MA, MIT Press, 1998,pp 461-488.

[24] Camus J, Gely-Nargeot M. Existe-t-il un vieillissement de l'attention? In Le vieillissement cognitif normal: vers un modèle explicatif du vieillissement. Edited by Brouillet D, Syssau A. Bruxelles, DeBoeck Université, 2000,pp 53-74.

[25] Greenwood P, Parasuraman R. Attention disengagement deficit in nondemented elderly over 75 years of age. Aging and Cognition 1994;1:188-202.

[26] Buck BH, Black SE, Behrmann M, Caldwell C, Bronskill MJ. Spatial- and object-based attentional deficits in Alzheimer's disease. Relationship to HMPAO-SPECT measures of parietal perfusion. Brain 1997;120 (Pt 7):1229-44.

[27] Eriksen C. The flanker's task and response competition: A useful tool for investigating a variety of cognitive problems. Visual Cognition 1995;2:101-118.

[28] Fan J, McCandliss BD, Sommer T, Raz A, Posner MI. Testing the efficiency and independence of attentional networks. J Cogn Neurosci 2002;14:340-7.

[29] Fan J, Flombaum JI, McCandliss BD, Thomas KM, Posner MI. Cognitive and brain consequences of conflict. Neuroimage 2003;18:42-57.

[30] Posner MI, Raichle M. Images of Mind. New York: Freeman and Company 1994,pp 1257.

[31] Balkenius C. Attention, Habituation and Conditioning: Toward a Computational Model. Cognitive Science Quarterly 2000;1:1-29.

[32] Gusella JF, Wexler NS, Conneally PM, Naylor SL, Anderson MA, Tanzi RE, Watkins PC, Ottina K, Wallace MR, Sakaguchi AY,Young AB, Shoulson I, Bonilla E, Martin JB. A polymorphic DNA marker genetically linked to Huntington's disease. Nature 1983;306:234-8.

[33] Riess O, Noerremoelle A, Soerensen SA, Epplen JT. Improved PCR conditions for the stretch of (CAG)n repeats causing Huntington's disease. Hum Mol Genet 1993;2:1523.

[34] Posner MI. Orienting of attention. Q J Exp Psychol 1980;32:3-25.

[35] Parasuraman R, Greenwood PM, Haxby JV, Grady CL. Visuospatial attention in dementia of the Alzheimer type. Brain 1992;115 (Pt 3):711-33.

[36] Jonides J, Mack R. On the cost and benefit of cost and benefit. Psychological Bulletin 1984;96:29-44.

[37] Chapman LJ, Chapman JP, Curran T, Miller MB. Do children and the elderly show heightened semantic priming ? How to answer the question. Developmental Review 1994;14:159-185.

[38] Curran T, Hills A, Patterson MB, Strauss ME. Effects of aging on visuospatial attention:an ERP study. Neuropsychologia 2001;39:288-301. 
[39] Lawrence AD, Hodges JR, Rosser AE, Kershaw A, French-Constant C, Rubinsztein DC, Robbins TW, Sahakian BJ. Evidence for specific cognitive deficits in preclinical Huntington's disease. Brain 1998;121 (Pt 7):1329-41. 


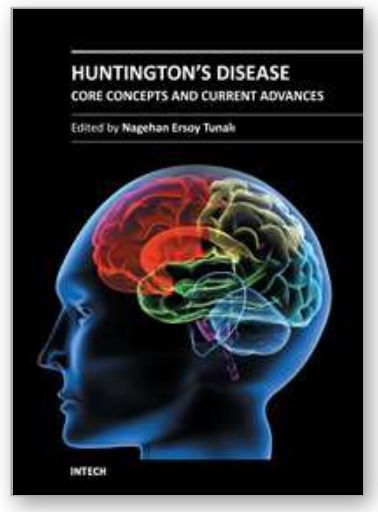

\author{
Huntington's Disease - Core Concepts and Current Advances \\ Edited by Dr Nagehan Ersoy Tunali
}

ISBN 978-953-307-953-0

Hard cover, 554 pages

Publisher InTech

Published online 15, February, 2012

Published in print edition February, 2012

Huntington's Disease is one of the well-studied neurodegenerative conditions, a quite devastating and currently incurable one. It is a brain disorder that causes certain types of neurons to become damaged, causing various parts of the brain to deteriorate and lose their function. This results in uncontrolled movements, loss of intellectual capabilities and behavioural disturbances. Since the identification of the causative mutation, there have been many significant developments in understanding the cellular and molecular perturbations. This book, "Huntington's Disease - Core Concepts and Current Advances", was prepared to serve as a source of up-to-date information on a wide range of issues involved in Huntington's Disease. It will help the clinicians, health care providers, researchers, graduate students and life science readers to increase their understanding of the clinical correlates, genetic aspects, neuropathological findings, cellular and molecular events and potential therapeutic interventions involved in HD. The book not only serves reviewed fundamental information on the disease but also presents original research in several disciplines, which collectively provide comprehensive description of the key issues in the area.

\title{
How to reference
}

In order to correctly reference this scholarly work, feel free to copy and paste the following:

Charles-Siegfried Peretti, Charles Peretti, Virginie-Anne Chouinard and Guy Chouinard (2012). Endogenous Attention in Normal Elderly, Presymptomatic Huntington's Disease and Huntington's Disease Subjects, Huntington's Disease - Core Concepts and Current Advances, Dr Nagehan Ersoy Tunali (Ed.), ISBN: 978-953307-953-0, InTech, Available from: http://www.intechopen.com/books/huntington-s-disease-core-conceptsand-current-advances/endogenous-attention-in-normal-elderly-presymptomatic-huntington-s-disease-andhuntington-s-disease-

\section{INTECH}

open science | open minds

\author{
InTech Europe \\ University Campus STeP Ri \\ Slavka Krautzeka 83/A \\ 51000 Rijeka, Croatia \\ Phone: +385 (51) 770447 \\ Fax: +385 (51) 686166 \\ www.intechopen.com
}

\author{
InTech China \\ Unit 405, Office Block, Hotel Equatorial Shanghai \\ No.65, Yan An Road (West), Shanghai, 200040, China \\ 中国上海市延安西路65号上海国际贵都大饭店办公楼 405 单元 \\ Phone: +86-21-62489820 \\ Fax: +86-21-62489821
}


(C) 2012 The Author(s). Licensee IntechOpen. This is an open access article distributed under the terms of the Creative Commons Attribution 3.0 License, which permits unrestricted use, distribution, and reproduction in any medium, provided the original work is properly cited. 